\title{
METAMORFOSES DA AUTORIDADE: APONTAMENTOS SOBRE A NOÇÃO DE AUTORIDADE NA CULTURA HODIERNA
}

\author{
METAMORPHOSES OF AUTHORITY: NOTES ON THE \\ NOTION OF AUTHORITY IN TODAY'S CULTURE
}

LAS METAMORFOSIS DE AUTORIDAD: NOTAS SOBRE
LA NOCIÓN DE AUTORIDAD EN LA CULTURA ACTUAL

Luiz Antônio CALmon Nabuco LastóRia ${ }^{\mathrm{I}}$

Juliana Rossi DuCI ${ }^{\mathrm{II}}$

Resumo Este artigo tem como objetivo apresentar as transformações verificadas no conceito de autoridade como este figura na tradição ocidental. Tomado em sua acepção etimológica latina enquanto elemento constitutivo da tradição romana, a discussão do conceito comporta as transformações sofridas sob os impactos provocados pela Modernidade: os abalos na vida familiar, social e econômica. Tais transformações atingem a produção da subjetividade hodierna na medida em que incidem em substratos tradicionais, como é o caso das figuras paterna e do professor, e também do próprio texto. Esse fenômeno tende a provocar alterações substantivas na compreensão da autoridade no campo da educação, em especial naquela modalidade que atualmente se expande no cenário brasileiro - a educação a distância. As digressões aqui apresentadas pautam-se pela crítica social psicanaliticamente orientada e conjecturam um possível deslocamento da autoridade tida como tradicional em direção aos novos suportes audiovisuais marcados pelo uso das Tecnologias da Informação e da Comunicação.

Palavras-chave: Autoridade; Teoria Crítica da Sociedade; Subjetividade; Tecnologias DA INFORMAÇÃO E DA COMUNICAÇÃO.

Universidade Estadual Paulista "Júlio de Mesquita Filho". Araraquara/SP - Brasil

II Universidade Estadual Paulista "Júlio de Mesquita Filho". Araraquara/SP - Brasil 
Abstract This article aims to present the concept of transformations such as this authority figure in the Western tradition. Taken in its Latin etymological while constitutive element of Roman tradition, the discussion of the concept involves the transformations suffered under the impacts caused by modernity: concussions in the family, social and economic life. Such transformations reach the production of subjectivity today the extent to which they apply traditional substrates such as paternal figures and the teacher, and the text itself. This phenomenon tends to result in substantive changes in the understanding of authority in the field of education, in particular in that mode currently expands in the Brazilian scenario - distance education. The tours presented here uphold the social criticism psychoanalytically oriented and assume a possible shift of authority considered traditional toward the new audiovisual brackets marked by the use of information and communication technologies.

Key-words: Authority; Critical Theory of Society; Subjectivit; Information and comMUNICATION TECHNOLOGIES

Resumen Este artículo tiene como objetivo presentar las transformaciones que el concepto de autoridad como esta figura en la tradición occidental. Tomada en su sentido etimológico América como un elemento constitutivo de la tradición romana, el concepto de la discusión consiste en las transformaciones experimentadas en los impactos causados por la Modernidad: conmociones cerebrales en la vida familiar, social y económica. Estos cambios afectan a la producción de la subjetividad de hoy en que se refieren a los sustratos tradicionales, tales como las figuras parentales y el profesor y también del propio texto. Este fenómeno tiende a provocar cambios sustanciales en la comprensión de la autoridad en el campo de la educación, especialmente en ese modo que en la actualidad se está expandiendo en la escena brasileña - la educación a distancia. Los recorridos que aquí se presentan son guiados por la crítica social y de orientación psicoanalítica suponen un posible cambio de la autoridad que se consideran tradicionales hacia los nuevos medios audiovisuales marcados por el uso de las Tecnologías de Información y Comunicación.

Palabras clave: Autoridad; Teoría Crítica de la Sociedad; La subjetividad; TecnologíAS DE INFORMACIÓN Y COMUNICACIÓN.

\section{NOTAS SOBRE O CONCEITO E DESLOCAMENTOS VERIFICADOS NA NOÇÃO DE AUTORIDADE}

Desde a chamada revolução científica ocorrida no século XVII as relações sociais entretecidas nas sociedades ocidentais mudaram drasticamente. Nas palavras de O. Matos: "o mundo vivido converte-se em uma abstração epistemológica, transformado em ideia, metamorfoseado em mundo pensado e representado" (MATOS, 2010, p. 216). Acreditava-se que esse novo mundo vivido, apesar das profundas mudanças, continuaria a manter os seus pilares e valores estabelecidos. Contudo, de acordo com W. Benjamin (1994), a Modernidade significou a passagem de um mundo com regras conhecidas para um mundo 
instável e incerto. O princípio da autoridade que antes nos fazia compreender e pertencer ao mundo, princípio pautado nas hierarquias instituídas, na obediência, na influência, na tradição, enfim nos valores morais estabelecidos, perdeu a sua força. Toda a compreensão de mundo social e político, como este havia se constituído no Ocidente a partir do legado grego apropriado pelos romanos, sucumbiu à Modernidade. Nas palavras de H. Arendt (2011, p. 130-131):

(...) perdemos o fio que nos guiou com segurança através dos vastos domínios
do passado, esse fio, porém, foi também a cadeia que aguilhoou cada sucessiva
geração a um aspecto predeterminado do passado [...]. Mas não se pode negar
que, sem uma tradição firmemente ancorada - e a perda dessa firmeza ocorreu
muitos séculos atrás - toda a dimensão do passado foi também posta em perigo.

Ao compreendermos a noção de autoridade a partir da tradição ocidental, considerando a sua pluralidade de acepções e significados históricos, será possível percebermos a relevância investigativa dessa noção para o mundo atual.

A premissa evidenciada por Adorno (1995, p. 176), segundo a qual: "o conceito de autoridade adquire seu significado no âmbito do contexto social em que se apresenta" nos serviu como sugestão para partirmos do verbete sobre esse termo contido no Dicionário de Educação (2012, p. 512). Lá encontramos a distinção entre o termo latino Potestas, que significa o poder baseado na função, na posição hierárquica e no estatuto. É o poder legal concedido pelas instâncias superiores da sociedade para tomar decisões e comandar em determinado domínio, recorrendo à coerção, caso necessário. E Auctoritas, que não é objeto de uma atribuição oficial, e sim da ordem da influência, da ascendência, do crédito, do respeito, da hierarquia em termos morais. A autoridade, nesse sentido, é a arte de obter adesão sem recorrer à ameaça ou à coerção.

A distinção entre esses termos é importante, pois determina, em muitos casos, não apenas o sentido dado à autoridade, mas, sobretudo, como essa se estabelece e se desenvolve. A palavra autoridade também se liga ao termo em latim autor, que, por sua vez, deriva do verbo augere, significando "aumentar". Sendo assim, a função primeira da autoridade é a de autorizar os indivíduos a existirem, a crescerem, a aprenderem, a serem conhecidos e respeitados no mundo em que estão inseridos. Tal ação se desenvolve no tempo, propondo suportes e mediações. Ela não se baseia em um ato de submissão cega, mas em um ato de reconhecimento partilhado pela tradição.

Assim, em consonância com os estudos de Arendt (2011), a autoridade ocupa a posição de mediação, de intercessão em relação aos "recém-chegados"; pois somente àquele que é imbuído de autoridade é que cabe tornar familiar, acessível, argumentável e discutível a ordem simbólica existente de modo que a cultura e o ambiente social adquiram inteligibilidade e plausibilidade.

Arendt (2011), ao discutir a noção de autoridade vinculando-a às raízes da crise da educação contemporânea, identificou que, na Modernidade, essa noção adquiriu certa feição retórica e passou a representar obediência no sentido de um comportamento heterô- 
nomo. Principalmente porque "certas noções, claras em sua distinção para todos os séculos anteriores, começaram a perder sua clareza e plausibilidade por terem perdido seu significado na realidade público-política" (ARENDT, 2011, p. 139). A perda de clareza e plausibilidade que Arendt (2011) aponta reflete certa confusão quanto à compreensão do conceito. Se, por um lado, este sempre esteve ligado à obediência, por outro, não se deve ao exercício do poder ou da violência. Para essa autora relações de autoridade não se assentam nem na razão comum (persuasão), nem no poder dos que mandam (força), mas sim na hierarquia cujo direito e legitimidade são reconhecidos por todos; a qual ambos os polos de uma relação mediada pela autoridade têm seu lugar estável predeterminado. A autoridade, nesse caso, significa tanto a "contraposição à coerção pela força como à persuasão através do argumento" (ARENDT, 2011, p. 129).

A constatação de certa confusão quanto ao conceito de autoridade por conta de suas transformações na Modernidade não descarta reflexões desenvolvidas por outros autores, os quais se empenharam em aprofundar o debate sobre o que se poderia considerar, ao menos a partir de Arendt (2011), como o ocaso moderno da autoridade. E o fizeram considerando, entre outros, os impactos provocados em nossa subjetividade moderna.

Para M. Horkheimer (1990), no texto “Autoridade e família”, escrito em 1936, a autoridade deve ser compreendida em sua unidade com determinadas tarefas prático-históricas num momento específico. Contudo, essa classificação não pode ser aplicada de forma mecânica, pois o papel da relação de autoridade em uma época, bem como, o seu teor específico, exercem influência sobre o significado psíquico de sua aceitação. As contribuições trazidas por Horkheimer iluminam justamente essa dinâmica ao apresentar os desdobramentos que as relações de autoridade representaram, e representam, na vida em sociedade desde os alvores do Iluminismo.

O pensamento burguês iluminista teve na luta contra a autoridade da tradição o seu principal foco. No esplendor da era moderna, pensadores como Kant, Locke, Voltaire, Descartes, Fichte afirmaram que o homem deve usar suas próprias faculdades intelectuais ao invés de se submeter às autoridades que sustentavam a ordem social vigente. Contudo, como aponta Horkheimer (1990), essa inversão frente à autoridade evidenciou uma tendência de transformar e enaltecer essa mesma noção, somente que agora compreendida enquanto Razão. Na luta travada contra a autoridade instituída pela tradição, a filosofia se incumbiu de preconcebê-la sob a forma de uma abstração crescente. Processo que encontra o seu ponto de apoio na categoria "indivíduo". Doravante este - o indivíduo - que agora deve atuar por conta própria abolindo as antigas autoridades, deverá ser capaz de tudo por seus próprios meios racionais. Porém:

\footnotetext{
...enquanto ele [trabalhador] dava crédito às ideias de liberdade e igualdade e à soberania absoluta da razão, tal como reinavam no último século, na realidade ele se sentia livre sob as próprias circunstâncias dadas, na realidade a sua consciência era ideológica, pois as autoridades não eram derrubadas, apenas se ocultavam atrás do poder anônimo da necessidade econômica ou como se costuma dizer, atrás da linguagem dos fatos (HORKHEIMER, 1990, p. 205).
} 
Verifica-se, então, um assujeitamento às circunstâncias; um amoldar-se impotente à realidade social. O indivíduo imerso em novas contradições sociais se encontrava sob uma nova e poderosa autoridade que então se estabelecia: a autoridade econômica. Os impactos provocados pela autoridade econômica capitalista refletiram, por sua vez, nas experiências vividas no interior da estrutura familiar. Pois essa instituição privada também passou a ser constituída por relações de dependência para com a esfera do trabalho e da troca de mercadorias. À autonomia do proprietário no mercado e na empresa privada correspondia à dependência da mulher e dos filhos em relação ao marido e ao pai: a autonomia privada pretensamente obtida nas relações de mercado se convertia, na vida familiar, em autoridade e tornava ilusório o pretenso livre-arbítrio dos indivíduos.

Essa relação de imanência entre os ditames econômicos provenientes do mercado capitalista sobre o âmbito da vida familiar penetra a dimensão subjetiva dos indivíduos. Aqui as reflexões proporcionadas pela psicanálise de S. Freud contribuem para uma compreensão mais acurada acerca da estruturação da psique dos indivíduos no seio da instituição familiar burguesa, e, por conseguinte, da atuação destes frente às exigências agora emanadas das novas instâncias de autoridade conformes ao mundo moderno.

Nos escritos "Totem e Tabu", de 1913-1914, Freud expõe sua compreensão acerca das raízes da dominação patriarcal. Ele parte da hipótese antropológica segundo a qual teria havido em tempos arcaicos uma "rebelião primordial" dos filhos contra o pai autoritário e despótico da horda primitiva. Esse pai despótico tomava para si todas as mulheres do grupo. O crime cometido pelos irmãos teria deixado marcas indeléveis na memória coletiva dos ascendentes, vinculando a sexualidade ao sentimento de culpa e à dor provocada pela ausência paterna, simultaneamente fonte de proteção e castração psíquica. De acordo com A. V. Azevedo (2001, p. 35), na visada psicanalítica tal "cena primeva" nos forneceria as bases para a elaboração da noção de Lei (autoridade), além de corroborar outras, como a da estrutura edipiana, a do desejo e a do próprio inconsciente enquanto o avesso da consciência humana.

Freud fortalece a sua premissa quanto à gênese da Lei - "rebelião primordial" - quando apresenta a sua versão da tragédia de Sófocles, Édipo Rei. O "complexo de Édipo", como Freud o formulou, seria o primeiro terreno de compreensão da desproporção entre o poder do pai e a impotência do filho. A partir da dinâmica pulsional engendrada na fase edipiana, Freud pôde confirmar a sua própria hipótese "mitológica" ao mostrar a plausibilidade dos antecedentes da Lei a partir do desejo erótico da criança, o medo suscitado pela fantasia de castração e a culpa brotada da vontade de eliminação da instância interditora.

Já os pensadores da primeira geração da chamada Teoria Crítica da Sociedade, por sua vez, lançam mão desse diagnóstico a fim de realizarem uma crítica social psicanaliticamente orientada, para melhor compreender a constituição da família burguesa. Uma instituição de características protestantes, a princípio, e cuja função do pai no seio familiar teve o seu papel modificado consideravelmente já na época do liberalismo; o que se acentuou quando da passagem às configurações familiares mais contemporâneas. No primeiro período, a autoridade acompanhou a figura do provedor econômico. Também por sua superioridade física sobre os filhos, o pai era, pois, o chefe "natural" e "racional" da família. 
Já no segundo período, mesmo com a perda relativa do status da figura paterna devido ao desaparecimento de sua base material provocada pelos processos de exploração crescente do capital, a autoridade ainda se manteve, como afirma Horkheimer (1990), em sua forma econômica, sendo determinante nas relações sociais. "A idealização da autoridade paterna, como se emanasse de um decreto divino, da natureza das coisas ou da razão, se revela, a um exame mais acurado, como a glorificação de uma instituição economicamente condicionada" (p. 232).

A autoridade desfavorecida no âmbito familiar representa uma série de consequências na vida social e cultural, em especial quando pensamos nas experiências formativas e escolares. Podemos visualizar essas transformações, bem como, as suas consequências, na indicação de três grandes períodos relativos ao desenvolvimento da família apresentada por E. Roudinesco em seu livro A família em desordem, de 2003, p. 12:

\begin{abstract}
Numa primeira fase, a família dita "tradicional" serve acima de tudo para assegurar a transmissão de um patrimônio. (...) Nessa ótica a célula familiar repousa em uma ordem do mundo imutável e inteiramente submetida a uma autoridade patriarcal (...). Numa segunda fase, a família afetiva cujo modelo se impõe entre o final do século XVIII e meados do XX (...) valoriza também a divisão do trabalho entre os esposos, fazendo ao mesmo tempo do filho um sujeito cuja educação sua nação é encarregada de assegurar. A atribuição da autoridade torna-se então motivo de uma divisão incessante entre o Estado e os pais, de um lado, e entre os pais e as mães de outro. Finalmente, a partir dos anos de 1960, impõe-se à família dita "contemporânea" - ou pós-moderna -, que une, ao longo de uma duração relativa, dois indivíduos em busca de relações íntimas ou realização sexual. A transmissão da autoridade vai se tornando então cada vez mais problemática à medida que divórcios, separações e recomposições conjugais aumentam.
\end{abstract}

\title{
A SOCIEDAdE FLEXíVEL E A MODIFICAÇÃo DA SUBJETIVIDAdE FRENTE À AUTORI- DADE DESLOCADA
}

A autoridade, que até aproximadamente meados do século XX se apresentava de modo quase natural, começou a ser questionada, sobretudo em uma sociedade na qual o mundo do trabalho passou a visar mobilidade e adaptabilidade flexível constante. Nesse tipo de sociedade, impermanência significa inovação, criatividade, competências estas valorizadas por sua capacidade de se adequar às necessidades de expansão dos mercados em prol do capital.

O sociólogo R. Sennett, em seu livro A corrosão do caráter: o desaparecimento das virtudes com o novo capitalismo afirma que os valores do mundo do trabalho flexível invadiram o ethos da vida familiar. Esta se dá conta de sua eclosão quando reflete acerca dos vínculos, da permanência conjunta e do pressuposto de algum padrão de autoridade vinculante para que a instituição perdure; aspectos esses que perdem seu sentido no atual mundo corporativo. Vemos que a sociedade possível num capitalismo ainda mais comple- 
xo e avançado não resiste à ácida erosão daquelas qualidades orientadoras de relações de longo prazo, como lealdade, compromisso, propósito e resolução.

Vivemos uma experiência de "tempos desconjuntados" na qual não há mais a ideia de "longo prazo". A necessidade de afrouxar os laços do tempo rotineiro e burocrático se impõe a fim de realizar especializações flexíveis demandadas pela produção descentralizada. Contudo, na revolta contra a rotina, a aparência de nova liberdade é enganosa.

\footnotetext{
O tempo nas instituições e para os indivíduos não foi libertado da jaula de ferro do passado, mas sujeito a novos controles do alto para baixo. O tempo da flexibilidade é o tempo de um novo poder. Flexibilidade gera desordem, mas não livra das limitações (SENNETT, 2012, p. 66).
}

Nesse novo cenário, que poderíamos chamar de um cenário regido por uma "nova ética do trabalho flexível", o poder se faz presente nas cenas superficiais do trabalho de equipe, mas a autoridade está ausente. Pois, numa hierarquia de trabalho a figura de autoridade pressupõe alguém que assuma a responsabilidade pelo poder que utiliza; no entanto as atuais técnicas de administração empregadas repudiam qualquer noção de autoridade. A autoridade se realiza na mudança permanente, ou seja, na flexibilidade, e não por intermédio de uma pessoa que a "encarne".

A desresponsabilização provocada por uma sociedade que privilegia a efemeridade e a flexibilização, contribuindo para um jogo de poder isento de autoridades encarnadas, acaba por gerar um novo tipo de caráter; em vez do homem motivado, surge o homem irônico. Apoiado em R. Rorty, Sennett (2012, p. 132) concebe a ironia como um estado de espírito "em que as pessoas jamais são extremamente capazes de se levar a sério, porque sempre sabem que os termos em que se descrevem estão sujeitos a mudanças, sempre sabem da contingência e fragilidade de seus vocábulos finais, e portanto, de seus eus".

Uma visão irônica de si mesmo é a consequência lógica do viver em um tempo flexível, sem padrões de autoridade e de responsabilidade. Esta é a normatividade investigada também por V. Safatle em Cinismo e falência da crítica (2008). Nesse livro o autor nos apresenta o cinismo, não a ironia, como uma categoria de análise das dinâmicas de racionalização em operação nas múltiplas esferas de interação social no capitalismo contemporâneo. Esferas essas compostas por um conjunto socialmente partilhado de sistemas de ordenamento e justificação de condutas no campo do trabalho, do desejo e da linguagem.

Devemos chamar de cinismo um problema geral referente à mutação nas estruturas de racionalidade em operação na dimensão da práxis. Há um modo cínico de funcionamento dessas estruturas que aparece normalmente em épocas e sociedades em processo de crise de legitimação, de erosão da substancialidade normativa da vida social. Isso nos coloca diante de uma hipótese maior: a partir de um certo momento histórico, os regimes de racionalização das esferas de valores da vida social na modernidade capitalista começaram a realizar-se (ou pelo menos, começaram a ser percebidos) a partir de uma racionalidade cínica. (...) E, enquanto processo de racionalização, o cinismo pode aparecer como 
posição discursiva em várias esferas da vida social (e não apenas no campo dos julgamentos morais) (SAFATLE, 2008, p. 13).

Temos então a erosão de formas tradicionais de vida e a abertura de espaço para a indeterminação e para o esvaziamento de toda substancialidade normativa do tecido social. Esse fenômeno é caracterizado pelo cinismo, o qual é capaz de transformar o "sofrimento da indeterminação normativa" em motivo de gozo. Tal discussão prossegue e se aprofunda quando retomamos o seu fio em meio aos debates travados no interior da psicanálise contemporânea. O homem sem gravidade: gozar a qualquer preço, de C. Melman (2008), psicanalista francês, em entrevista concedida a J. P. Lebrun, reflete sobre uma constatação verificada em seu consultório: onde antes se buscava encontrar saída da neurose desejante, vê-se, com frequência, a fala sobre um enviscamento num gozo excessivo. Para o psicanalista, vivemos uma "crise das referências", onde não há mais autoridade, ideologias, promessas, prescrições ou saberes que sustentam balizas para tomadas de decisão - estamos apenas na gestão, há apenas práticas. E desse modo:

\footnotetext{
...estamos lidando com uma mutação que nos faz passar de uma economia organizada pelo recalque a uma economia organizada pela exibição do gozo. Não é mais possível hoje abrir uma revista, admirar personagens ou heróis de nossa sociedade sem que eles estejam marcados pelo estado específico da exibição do gozo. Isso implica deveres radicalmente novos, impossibilidades, dificuldades e sofrimentos diferentes (MELMAN, 2008, p. 16).
}

Segundo Melman (2008), passamos de um regime pautado pela representação, regime esse que nos é tão familiar, à preferência por "presentações", por meio das quais se busca o autêntico, o encontro com o objeto. Temos assim o apagamento dos limites, de modo a se obter cada vez mais proximidade, transparência e exibição. Por essa via nos tornamos consumidores adictos, ávidos por possuir objetos. Tal realidade, para Melman (2008), tende a nos tornar mais propensos às linguagens icônicas do que as alfabéticas, pois para ele a imagem já não funciona mais conforme o registro da representação, mas sim como exibição. E, nesse sentido, em uma sociedade de práticas e linguagens predominantemente técnicas, e na qual o gozo excessivo se tornou um imperativo, a autoridade mesma tende a ser eliminada, ao menos naquela forma que Melman (2008) a compreende, isto é, como constituinte do próprio limite do exercício do poder.

Evidencia-se assim alguns aspectos que, sob a influência de uma sociedade flexível, excessiva e cínica, impactam sobremaneira nossa subjetividade. Esta tende a se realizar de modo cada vez mais por meios imagéticos e performáticos com o intuito de satisfazer necessidades que não podem mais ser adiadas.

Partimos da ideia exposta por Arendt, segundo a qual o "fio que nos guiou" - tradição - foi rompido. E estamos de acordo com V. Flusser (2011), quando este afirma que somos, atualmente, testemunhas, colaboradores e vítimas de uma revolução cultural cujo principal sintoma é a emergência das imagens técnicas à nossa volta. Imagens que podemos compreender como resultado das modificações processadas em nível da vida econômica, e também 
de nossa subjetividade. Fenômeno constituinte e constituído pelo próprio desenvolvimento da sociedade de consumo hodierna, e que impacta a configuração da instituição família e a (in) compreensão da autoridade sob a qual essa instituição se assentava.

Fotografias, filmes, imagens de TV, de vídeo e dos terminais de computador assumem o papel de portadores da informação outrora desempenhado por textos lineares. Não mais vivenciamos, conhecemos e valorizamos o mundo graças a linhas escritas, mas agora graças a superfícies imaginadas. Como a estrutura da mediação influi sobre a mensagem, há mutação na nossa vivência, nosso conhecimento e nossos valores. O mundo não se apresenta mais enquanto linha, processo, acontecimento, mas enquanto plano, cena, contexto. (...) As imagens tradicionais são superfícies abstraídas de volumes, enquanto as imagens técnicas são superfícies construídas com pontos (FLUSSER, 2011, p. 15-16).

Em decorrência dessas transformações as categorias sobre as quais nos identificamos e interagimos com o mundo se modificam em processos de substituição, transformação e deslocamento. E desse modo, podemos, talvez, estar nos deparando com um novo paradigma da autoridade que agora tende a encontrar suporte nos meios técnicos imagéticos, o que pode representar uma nova maneira de compreendermos o processo formativo e seus impactos na vida em sociedade.

\section{TECNOIMAGENS: UM NOVO SUPORTE PARA A AUTORIDADE NA SOCIEDADE ATUAL?}

As metamorfoses ocorridas nas relações pautadas pela noção de autoridade ao longo da vida moderna impactaram de modo significativo as novas relações familiares, sociais, culturais e econômicas. Contudo, um campo específico e essencial da vida em sociedade também sofreu injunções a partir das alterações verificadas na compreensão daquela noção: os processos formativos; e, em especial, aqueles mediados pelos suportes técnicos imagéticos cada vez mais presentes na ambiência educacional.

De acordo com Arendt (2010, p. 245):

$\mathrm{Na}$ educação a responsabilidade pelo mundo assume a forma de autoridade. Quando um educador se recusa a assumir tal autoridade frente a uma criança, isso só pode significar que os adultos se recusam a assumir a responsabilidade pelo mundo ao qual trouxeram as crianças. O desaparecimento deste senso comum nos dias atuais, caracterizado pela não responsabilização dos adultos pelo mundo é um sinal mais seguro da crise na educação.

No Brasil, assistimos hoje tal processo de desresponsabilização e modificação da compreensão da autoridade no campo da educação, sobretudo quando constatamos ${ }^{1}$ o impacto

LASTÓRIA, L. A. C. N. DUCI, J. R. Educação, políticas e os meios de comunicação no Brasil: Da era do rádio à Internet. In: Constelaciones. Revista de Teoria Crítica n. 6 (Diciembre, 2014) - ISSN 21729506. Disponível em: http://www.constelaciones-rtc.net/06/CRTC_06_2014.pdf 
que as atuais propostas pedagógicas vêm produzindo na formação das novas gerações. O que ao mesmo tempo se refletiu no modo como a autoridade foi, e vem sendo compreendida nas diferentes modalidades de ensino, presencial e a distância.

A partir de ressignificações próprias à vida moderna, como: a valorização da individualidade, a instrumentalização do mundo e as atividades orientadas à produção e ao consumo; vemos o surgimento de orientações político-pedagógicas cuja finalidade persiste em fazer que os alunos venham a se inserir na sociedade de modo a torná-los órfãos em relação às responsabilidades educacionais e pedagógicas. E isto vale tanto para as instituições de ensino, quanto para as famílias.

J. Carvalho (2015) nos auxilia a compreender essa possível "passagem de bastão". O autor argumenta no sentido de uma dificuldade na aceitação da necessidade de submissão prévia à autoridade como condição de constituição do sujeito autônomo. Essa dificuldade tem levado os discursos educacionais vinculados às chamadas pedagogias do "aprender a aprender" 2 a um interminável combate programático em favor da abolição de toda e qualquer referência a um lugar de autoridade no que diz respeito à relação entre professores e alunos.

Combate que inclui até mesmo a tentativa de abolição desses termos, identificados como signos de uma ordem tradicional e hierárquica. Nesses discursos, fala-se em crianças e jovens, mas não em alunos; em facilitadores da aprendizagem ou parceiros mais experientes, mas não em professores. Fala-se em aprendizagem ou construção de conhecimento, mas não em ensino ou transmissão de um legado de experiências simbólicas. O efeito dessa ênfase discursiva na ação e no pensamento do sujeito que aprende tem sido o declínio da função mediadora do ensino e da transmissão como elemento de ligação social e temporal (CARVALHO, 2015, p. 983).

As ações que rejeitam a autoridade escolar como traço constitutivo da experiência formativa apenas favorecem a emergência e a consolidação de seu simulacro. Autoridade agora parece soçobrar deslocada para os novos suportes e aparatos, como os imagético/ midiáticos do tipo tecnológico-digitais.

Certa visão crítica dos discursos pedagógicos atuais nos conduz ao estabelecimento de um juízo sobre uma razão voltada quase que exclusivamente à administração, e à mera adaptação como objetivo maior de ser de um processo em que a autoridade docente é posta em xeque. Isto na medida em que se limitam cada vez mais as condições de escolha quanto à mediação entre o velho e o novo necessária à atualização e ressignificação do mundo. Somente numa perspectiva crítica:

...a educação adquire o aspecto conservador. Conservar o mundo, as suas instituições preparando os mais jovens para renová-lo e é por essa renovação que o mundo é conservado - essa é a condição da educação escolar. É por esse motivo que não cabe ao professor determinar o novo, mas preparar os mais jovens para

2 Uma perspectiva crítica às pedagogias do aprender a aprender pode ser encontrada nos escritos de N. Duarte, Sobre o Construtivismo: contribuições a uma análise crítica 2. ed. Campinas, SP: Autores Associados, 2005. 
que de fato o novo possa emergir. E não por determinar o novo, mas tendo como finalidade prepará-lo, que o professor não carece de estar atualizado com as últimas determinações da ciência e da tecnologia que ainda são fugazes, mas precisa lidar com os saberes experimentados, já sedimentados no mundo. A responsabilidade dos professores está em apresentar o mundo para os jovens (GONÇALVES, 2012, p. 74).

Contudo, tal visão não apresenta grande prestígio atualmente; e as concepções epistemológicas vigentes continuam servindo ao desenvolvimento de metodologias que se materializam em práticas didático-pedagógicas consonantes ao desenvolvimento econômico e tecnológico. A compreensão que o professor venha a ter sobre a sua própria autoridade, assim como a compreensão que os alunos e as instituições de ensino formam sobre tal questão apenas fortalece aspectos da assim chamada "crise de autoridade na educação".

Conforme os "Padrões de Competência em TIC para Professores (ICT-CST)", responder aos desafios de uma formação no contexto da nova sociedade flexível requer a utilização de um referencial para o planejamento de programas de formação e de capacitação docente. O objetivo é o de que estes possam contribuir para a formação de alunos competentes no manuseio de diferentes tecnologias de informação e comunicação (TIC). As mesmas que subsidiam de modo efêmero a entrada das novas gerações em setores do atual mercado de trabalho, cada vez mais competitivo.

Por esse motivo, e considerando a função social dos formadores das novas gerações, os professores em atividade necessitariam desenvolver competências que lhes possibilitassem propiciar aos alunos oportunidades de aprendizagem a partir do uso de diferentes recursos imagéticos e ferramentas tecnológicas digitais. Tais diretrizes possuem grande repercussão nas mais variadas políticas educacionais ${ }^{3}$ em nosso país, o que nos permite inferir que esta seja uma tendência basilar para o processo formativo vigente; e, concomitantemente, uma referência objetiva para pensarmos a significação da autoridade nos processos educativos, sobretudo em plataformas direcionadas pelas TIC. Tal tendência ilustra nossa suspeita de que novos suportes emergem como ancoradouros da autoridade em meio à cultura atual.

Num cenário em que as tecnologias e seus mais variados suportes tomam a dianteira, a autoridade formativa do docente surge como elemento a ser cada vez mais interpelado. As vertiginosas transformações ocorridas desde o início da Modernidade até os dias atuais parecem indicar deslizamentos (ou deslocamentos) que a autoridade sofreu (e ainda sofre) quando supomos a sua necessidade considerando as relações intergeracionais. Em outras palavras: a responsabilidade das gerações mais velhas inserirem as gerações mais novas no mundo compartilhado por todos é o que nos parece claudicar quando vislumbramos as tendências hegemônicas relativas à utilização dos meios tecnológicos na educação.

3 Listo algumas políticas públicas relacionadas ao contexto educacional e as TIC: o Programa Banda Larga nas Escolas; o Programa Computador portátil para Professores, o Programa Nacional da Informática na Educação PróInfo, o Projeto Um Computador por Aluno - UCA, bem como a Universidade Aberta do Brasil - UAB, o Programa Escola Técnica Aberta do Brasil - e-Tec, entre muitos outros. 


\section{REFERÊNCIAS}

ADORNO, Theodor W. Educação e Emancipação. Rio de Janeiro: Paz e Terra, 1995.

ALMEIDA, Maria Elizabeth Bianconcini de. Educação, ambientes virtuais e interatividade. In: Educação online. São Paulo: Edições Loyola, 2012, p. 203-218.

ARENDT, Hannah. Entre o Passado e o Futuro. São Paulo: Perspectiva, 2011.

AZEVEDO, Ana Vicentini. A metáfora paterna na psicanálise e na literatura. Brasília: Editora Universidade de Brasília, 2001.

BELLONI, Maria Luiza. Educação a distância, 6. ed. Campinas: Autores Associados, 2012.

BENJAMIN, Walter. Magia e Técnica, Arte e Política: ensaios sobre literatura e história da cultura. São Paulo: Brasiliense, 1994.

BRASIL. Referenciais de Qualidade para Educação Superior a Distância. Brasília: Ministério da Educação, Secretaria de Educação a Distância, 2007. Disponível em: <http:// portal.mec.gov.br/seed/arquivos/pdf/referenciaisead.pdf $>$. Acesso em: 4 jan. 2016.

CARVALHO, José Sérgio Fonseca de. Autoridade e Educação: o desafio em face do ocaso da tradição. Revista Brasileira de Educação, v.20, n.63, out/dez. 2015, p. 985-993. Acessa-

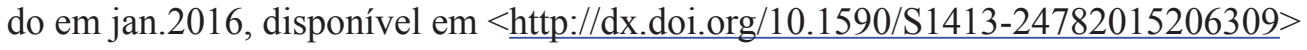

DUARTE, Newton. Sociedade do conhecimento ou sociedade das ilusões? Quatro ensaios crítico-dialéticos em filosofia da educação. Campinas: Autores Associados, 2003.

DUCI, Juliana Rossi. Prejuízos Educacionais: a semiformação intensificada. Dissertação (Mestrado em Educação Escolar) - Universidade Estadual Paulista "Júlio de Mesquita Filho", Faculdade de Ciências e Letras (Campus de Araraquara), 2014.

FLUSSER, Villém. Filosofia da Caixa Preta: ensaios para uma futura filosofia da fotografia. São Paulo: Annablume, 2011.

FREUD, Sigmund. Totem e Tabu e outros trabalhos (1913-1914). Volume XIII. São Paulo: Editora Imago, 2006, p. 21-162.

GONÇALVES, Tânia. Autoridade docente: pensamento, responsabilidade, reconhecimento. Tese (Doutorado) - Programa de Pós-Graduação em Educação - Faculdade de Educação da Universidade de São Paulo, 2012.

HORKHEIMER, Max. Autoridade e Família. In: Teoria Crítica: uma documentação. São Paulo: Perspectiva Editora da Universidade de São Paulo, 1990, p. 175-236.

MATOS, Olgária Chain Féres. Benjaminianas: cultura capitalista e fetichismo contemporâneo. São Paulo: Editora UNESP, 2010.

MELMAN, Charles. O homem sem gravidade: gozar a qualquer preço. Rio de Janeiro: 
Companhia de Freud, 2008.

RIPA, Roselaine. Reflexões sobre o "ser professor" na EAD: estamos diante de uma descaracterização do trabalho docente? In: Revista Comunicações, Piracicaba, Ano 22, n. 3, p. $75-85,2015$.

ROUDINESCO, Elisabeth. A família em desordem. Rio de Janeiro: Jorge Zahar, 2003.

SAFATLE, Vladimir. Cinismo e falência da crítica. São Paulo: Boitempo, 2008.

SCHELEMMER, Eliane. Políticas e práticas na formação de professores a distância: por uma emancipação digital cidadã. In: GATTI, Bernadete Angelina et al. (org.). Por uma política nacional de formação de professores. São Paulo: UNESP, p. 109-136, 2013.

SENNETT, Richard. A corrosão do caráter. O desaparecimento das virtudes com o novo capitalismo. Rio de Janeiro: Bestbolso, 2012.

UNESCO. Padrões de competências em TIC para professores, 2009.

ZANTEN, Agnés van. Dicionário de Educação. São Paulo: Editora Vozes, 2012.

\section{Dados dos Autores}

\section{Luiz Antônio Calmon Nabuco Lastória}

Doutor em Psicologia pela Universidade de São Paulo. É Professor Livre-Docente no Departamento de Psicologia da Educação na Universidade Estadual Paulista "Júlio de Mesquita Filho". Araraquara/SP - Brasil. lacalmon@ffclar.unesp.br

\section{Juliana Rossi Duci}

Doutoranda do Programa de Educação Escolar na Universidade Estadual Paulista "Júlio de Mesquita Filho". Araraquara/SP - Brasil. juhduci@gmail.com

Submetido em: 1-4-2016

Aceito em: $30-3-2017$ 